\title{
SOBRE JORGE CUESTA
}

Verónica Volkow*

RESUMEN: Jorge Cuesta, en su ensayo "Robert Desnós y el sobrerrealismo" relata cómo éste lee y escucha directamente, en un mismo día, el mismo suceso acaecido tanto a Baudelaire como a Breton. A su vez, Cuesta es consciente de que al escribir acerca de Desnós se está retratando a sí mismo, viéndose como en un espejo, donde refleja su imagen que es igual y a la vez independiente del emisor de la imagen.

শ্ৰ

ABSTRACT: Jorge Cuesta writes an essay about Robert Desnós and surrealism; in this paper relates how he read and listen, in the very same day, the very same event that took place with Baudelaire and Breton. At the same time, Cuesta tells how, while writing about Desnós, he is describing himself, as in a mirrow that reflects his image that is independent from him.

PALABRAS ClaVE: Robert Desnós, Jorge Cuesta, André Breton, surrealismo, vacío existencial. KEYWORDS: Robert Desnós, Jorge Cuesta, André Breton, surrealism, existencial vacuum. RECEPCIÓN: 21 de mayo de 2008.

ACEPTACIÓN: 22 de mayo de 2008.

* Poeta. 
La reproducción total o parcial de este artículo se podrá hacer si el ITAM otorga la autorización previamente por escrito. 


\section{SOBRE JORGE CUESTA}

En su ensayo "Robert Desnós y el sobrerrealismo", Jorge Cuesta relata una extraña anécdota: tras haber estado una tarde leyendo Los paraísos artificiales de Baudelaire oye esa misma noche a Breton contar su experiencia con el hachís. Con sorpresa observa que el relato de Breton coincide punto por punto con la narración de Baudelaire que venía de estar leyendo: "Había dos hechos iguales, pero eran dos hechos distintos, y los he comparado entre sí con la misma sorpresa con la que hubiera visto a mi imagen en el espejo vivir independientemente, saludarme y marcharse sin que yo me moviera."1

La extrañeza ante estos caminos paralelos: la coincidencia de un Breton comentando, ante Cuesta, una experiencia semejante a la que vivió Baudelaire, y él, Jorge Cuesta, acabando en el mismo día de leer a Baudelaire, es ilustrada mediante la imagen de un espejo independiente. La imagen en el espejo es la propia, pero sorpresivamente se despide, sigue un camino propio. Hay una separación dentro de una incuestionable identidad, una serie de experiencias muy similares y no obstante independientes, sin una lineal causa efecto entre ellas. E1 espejo independiente, a pesar de su fidelidad, no ancla ni determina un destino, sino que abre una puerta hacia lo imprevisto. La imagen en este espejo está encadenada por la semejanza, pero a la vez, es inopinadamente libre.

Jorge Cuesta se identifica con Robert Desnós y su destino libertario tan celebrado por André Breton. ${ }^{2}$ La trayectoria radicalmente indepen-

${ }^{1}$ Jorge Cuesta, "Robert Desnós y el Sobrerrealismo”, Poemas y ensayos, 1964, México, UNAM, vol. II, p. 67.

2 "Demandez a Robert Desnós, celui d'entre nous qui, peut être le plus proche de la verité surréaliste, celui qui dans des oeuvres encores inédites et le long des multiples expériences 
VERÓNICA VOLKOW

diente que fue la de Desnós quien "no hace nada para retener las hojas que se vuelan al viento de su vida", 3 en palabras de Breton, es también un secreto espejo para el autor del Canto a un dios mineral. Ambos destinos se asemejan por su rechazo a determinaciones previstas y su generosa apertura a una impulsiva creatividad. Sobre la pasión libertaria de Desnós, Cuesta escribe lo que también podría aplicarse a sí mismo: "Frente a una vida impulsiva y generosa pocos tienen fuerza para respetar la libertad de su misterio."4

Estas hojas de la vida que vuelan sin la constricción de ser retenidas del retrato que hace Breton de Desnós, son también como el espejo independiente, donde la propia imagen se desprende sin quedar aprisionada. Hay en este espejo abierto a la puerta de la sorpresa y en estas hojas de la vida que escapan sin amarras una interna semejanza. Cuesta, quien gusta de los retratos simbólicos, trazará un dibujo alegórico de Desnós:

Un punto sobre una curva regular se localiza con el conocimiento de su ley, refiriéndolo a los otros puntos cuya uniformidad repite; pero sobre una curva irregular que no hay ley que fije la posición de los puntos dispersos: cada uno se debe, si acaso, existiendo en su propio vértice, a la influencia de los más próximos, de los idénticos a él, y a lo largo de la curva, sobre cada punto se revela una diferencia y se manifiesta una libertad. Así el espíritu de Desnós, así su presencia. ${ }^{5}$

En esta línea de puntos imprevisibles que ilustra la trayectoria vital de Desnós, podemos encontrar un paralelismo con las metáforas plásticas del espejo independiente y de las hojas que vuelan. Cada

auxquelles il s'est prêtè, a justifié pleinement l'espoir que je placais dans le surréalisme et me somme encore d'en attendre beaucoup. Auhjourd'hui Desnos parle surréaliste à volonté. La prodigieuse agilité qu'il met à suivre oralement sa pensé nous vaut autant qu'il nous plaît de discours splendides et qui se perdent. Desnos ayant mieux à faire que'à les fixer. Il lit en lui à livre ouvert en te fait rien pour retenir les feuillets que s'envolent au vent de sa vie", Breton, Oeuvres Completes, Manifeste du surréalisme, 1988, Paris, Gallimard, p. 331.

${ }^{3}$ Citado por Cuesta, "Robert Desnós y el sobrerrealismo", op. cit., p. 66.

${ }^{4}$ Ibid., p. 68.

${ }^{5}$ Ibid., p. 66. 
punto de la línea irregular es imponderable, su posición no puede ser calculada por la trayectoria de los otros puntos. De igual manera, es imposible predeterminar la acción que realiza la imagen del espejo independiente; tampoco pueden atarse las hojas sueltas. No hay una ley que fije de antemano la posición del momento disperso ni en el recorrido de la audaz línea extraordinaria, ni en el espejo independiente, tampoco en esa vida del poeta entre sus hojas que saltan.

Cuesta leyendo a Baudelaire sería como Breton quien, a pesar de la secreta identidad con el ancestro poeta, se mantiene libre. Cuesta es a su vez como Desnós, por la similitud de vocaciones libertarias. En todos estos extraños encuentros dos seres se identifican un momento -como un ser frente a su imagen en el espejo- pero después parten cada uno en una dirección misteriosa.

Hay en el espejo independiente un juego dialéctico de opuestos, convive la fidelidad a lo real junto con la sorpresa imponderable. El espejo no inventa su realidad, está anclado a una semejanza a la vez que lo impulsa su propio albedrío.

Habría un símbolo representativo de la postura de Cuesta en este 'espejo independiente': Cuesta no cultiva una realidad hermética, idealizada y desconectada de lo dado; no se fuga en la ficción, ni construye evasivo su mundo de marfil a espaldas del existente, como lo señala Luis Panabière. ${ }^{6}$ Estamos ante un poeta que construye una disciplinada búsqueda de conocimiento de lo real, a partir de la cual desarrolla su propuesta creativa: la fidelidad a las condiciones de lo real es el punto de partida del itinerario artístico e intelectual de Cuesta.

Esta raigambre científica a lo dado podría simbolizarse mediante el juego de semejanzas del espejo, a la que se contrapone en un segundo momento, la despedida imprevisible, una suerte de segundo nacimiento hacia la libertad. "En su poesía, señala Panabière, no se comprueba la carencia, sino un deseo de conocimiento, y si éste se ve frustrado sólo

6 “Cuesta no inventa en su espíritu una presencia ideal que sustituiría a la real. Construye esta presencia a partir de lo que queda de lo percibido", Luis Panabière, Itinerario de una disidencia, 1996, México, FCE, p. 137. 
VERÓNICA VOLKOW

es para ser llevado más lejos, más allá del conocimiento intuitivo, a fin de constituirse en el sentido etimológico de conocerse: co-naître."7

El acto de conocer, vinculado a lo real, da lugar a un siguiente momento: un dar a luz o darse a luz. Panabière vincula lúdicamente los significantes, naître y co-naître, hay un darse nacimiento a sí mismo, un co-nacerse en conjunción con el conocer. Esta posibilidad de autoalumbramiento inaugura una vertiente inédita a la del paradigma tradicional del espejo mimético como emblema privilegiado de la poética clásica.

El espejo, que ha sido el símbolo más socorrido para ilustrar la naturaleza de la obra poética, se nos muestra aquí bajo un nuevo signo: es un espejo no sólo asociado al imitar o conocer lo realidad sino que induce a un nacimiento. La asociación con la vieja mayéutica socrática es inevitable; además de reflejar la verdad de lo real, el espejo da a luz al sujeto interpelado: al dar a luz lo verdadero también da a luz al sujeto nacido por y para el conocimiento. Cuesta, en tanto que poeta también, gracias el espejo independiente, accede a un alumbramiento.

Es un espejo que plasma una rigurosa impresión de lo real, como el espejo de la mímesis clásica, pero se diferencia de éste en que no es el testimonio de la presencia mediante la imagen mimética lo que celebra, sino que busca el hueco que deja esta presencia al desvanecerse. El hueco será principio de la maquinaria poética de Cuesta. Es la ausencia, el hueco, el vacío, el rastro lo que adquieren relieve en el espejo cuestiano:

Tu voz es un eco, no te pertenece, no se extingue con el soplo que la exhala.

Tus pasos se desprenden de ti

y hacen caminar un fantasma intangible y perpetuo que te expulsa del sitio donde vives tan pasajeramente te suplanta. ${ }^{8}$

7 "Para Jorge Cuesta no se trata de rechazar el conocimiento de lo real en la medida en que éste no es suficiente, en la medida en que no es capaz de conducir a una plenitud, a una totalidad, a una comunión", ibid., p. 130.

${ }^{8}$ Cuesta, "Tu voz es un eco, no te pertenece", Poemas y ensayos, UnAM, vol. I, p. 56. 
El espejo clásico persigue mediante su mímesis a la presencia del mundo, pero el de Cuesta atesora la concavidad de la ausencia, para en este hueco abrir la posibilidad de la subjetividad, y que de esta carencia nazca el sujeto poético.

El primer plano del espejo en Cuesta registra lo transitorio y fugaz de la realidad. Panabière observa que "el primer elemento notable es la puesta en relieve de la fragilidad de la realidad tangible, su cuestionamiento." Y agrega que la mayoría de los sonetos de Cuesta "se desarrollan en torno al eje de un acto en el espacio: el área de la realidad y su inconsistencia". ${ }^{9}$ El primer registro semántico y léxico de las imágenes de esta poesía es "el de la fragilidad, la caducidad y la fluidez". ${ }^{10}$ Ese énfasis en lo transitorio le permitirá a Cuesta apoderarse con presteza del molde que deja la realidad en su fuga.

El segundo eje semántico, según Panabière, gira alrededor de la noción de avidez, sed, vacío como vocación. Más allá de la materia que decepciona la búsqueda de una plenitud, existe la conciencia dinámica de la sed, del impulso provocado por esa espera, ese 'tender hacia'. ${ }^{11}$ La sed y el vacío se tornan elementos dinámicos. Ausencia y decepción no dan lugar a la queja sino al impulso. Y el impulso "no es una fuga de la realidad, sino su más intensa realización". ${ }^{12}$

En esta dinámica poética el hueco y el vacío se vuelven incitaciones para la emergencia de la subjetividad creativa. A partir de este hueco, el poeta emprende el camino de una búsqueda; intentará levantar su propio proyecto, un nuevo orden armado con elementos del mundo externo pero creado por su ser interior: "es en el proyecto, en el deseo realizado donde se halla la verdadera existencia, el sentido que el hombre puede y debe darse". ${ }^{13}$

${ }^{9}$ Panabière, op. cit., p. 92.

${ }^{10}$ Ibid., p. 95.

11 "La toma de conciencia de la fragilidad de la realidad es también la de una apertura que por el contrario se encuentra en el origen de un movimiento dinámico", ibid., p. 98.

12 "El poeta no llora su decepción pues encuentra en ella el camino del impulso, esa 'inmensa comarca' de que hablaba Apollinaire”, idem.

${ }^{13}$ Ibid., p. 100. 
El espejo y su imagen son tan poco fiables como la realidad que envuelve al poeta; pero esta naturaleza casi líquida del espejo, totalmente inestable, abismal de muchas formas, se convierte en el elemento primigenio de una segunda génesis. La carencia es aquí no sólo hueco o cicatriz en el espejo, sino una suerte de hendidura uterina que le permite al yo del poeta nacer bajo nuevas coordenadas. Más allá de la repetición del reflejo, hay una nueva fuerza que surge desde la ausencia.

Los seres y objetos del mundo externo escapan, no pueden retenerse, víctimas de un tiempo y espacio fragmentados; pero, por ello mismo, la imagen podrá ganar su independencia y podrá despedirse, marcharse, inaugurar camino suelto; requerirá, para ello, la disciplina del poema.

La dinámica del espejo cuestiano no privilegia la mímesis de una acción como la poética de Aristóteles. ${ }^{14}$ Aunque absorbe la impronta de lo externo, la imagen no persigue imitativamente al mundo. La imagen ha tomado una dirección 'libre y misteriosa'. El movimiento y la energía de esta imprevista salida se extraen a partir del vaciamiento de la presencia del mundo. Es como si el espejo de Cuesta sustrajera su energía del movimiento con que se escapa, muere, se desvanece o derrumba la vida. Es la sed y la carencia lo que lo impulsan: "La sombra sólo y la oquedad habita,/como su ausencia vanamente inunda/cuando es ficticio su fulgor y abunda,/ la vida que a su sed se precipita." 15

Hay una operación inédita sobre el espejo mimético que Cuesta realiza situándose de manera inversa respecto al movimiento del tiempo, no dando la cara a lo que existe y surge, en una actitud de espera o de voluntad de retención, sino buscando en sentido contrario lo que se desvanece o pierde. Cuesta mira desde el envés a la presencias, desde las huellas que serán de su pasado, desde el lugar de su sombra, desde su prometida ausencia; acecha el desprendimiento: "tus plantas de aire se aman en mi suelo/ y te me vuelves casi compañera”. Cuesta, de hecho, anhela el adiós, ama la pérdida.

\footnotetext{
${ }^{14}$ Aristóteles, Poética, 1974, Madrid, Gredos, p. 145.

${ }^{15}$ Cuesta, "La sombra sólo y la oquedad habita", UNAM, vol. I. p. 49.
} 
Es un espejo el de Cuesta que tiene dos caras, mira lo real, sí, pero por otro lado lo vacía y, al vaciarlo, captura la inercia de ese movimiento de huída, se opone al deseo de mantener la presencia y sostener miméticamente la representación: "se me aniquila el gesto del abrazo./ Y te pido un amor que no cohiba/ porque sujeta más con menos lazo". ${ }^{16}$ Es mediante esta energía robada a lo que se pierde o desmorona que nace la maquinaria poética de Cuesta, invirtiendo el espejo de la mímesis representativa para destilar, a partir de la ausencia, energía.

Podemos encontrar cuatro transmutaciones en el camino hacia el 'espejo independiente' de la poética cuestiana. La primera parte de la naturaleza mimética del espejo clásico que invierte el mundo en la imagen; la imagen es en sí misma una inversión de la realidad en el espacio, derecho versus izquierdo, pero también una transformación del objeto corporal y tangible en imagen bidimensional. Las imágenes gráficas y los reflejos son importantes en esta poesía, constituyen puntos de partida de poemas fundamentales como Dibujo o Canto a un dios mineral.

Pero lo específico en Cuesta es el segundo movimiento del espejo: después de invertir el mundo en el espacio plano, como todo espejo procede, hay un vaciamiento de la imagen mediante una operación sobre el tiempo. El espejo cuestiano captura por el revés al tiempo; es un espejo que no enfoca lo que se queda y está, sino cautiva de manera inversa lo que se escurre o desintegra. Es un espejo cazador de la ausencia, no de la presencia.

La poética de Cuesta tiene también un tránsito que va del mundo objetivo a la subjetividad, y ello ocurre a partir del lugar del hueco, de la ausencia. La avidez, la sed, el vacío ganan consistencia y surge el cuerpo del sujeto deseante. ${ }^{17}$ Mediante un cuerpo construido de vacío el poeta define su verdadero ser: "Lo que pasa por mí no es igualado/ y repuesto después de que aparece / su ausencia sólo soy que permanece." ${ }^{18}$

16 "Signo Fenecido", ibid., p. 48.

${ }^{17}$ Éste es el gran descubrimiento teórico de Panabière.

18 "Fundido me soñé al placer que aflora", ibid., p. 48. 
El yo subjetivo buscó deliberadamente la huella de lo ido para constituirse. El hueco será molde para el sujeto poético. Estamos ante un hueco dador de vida que creó mediante la sed que provoca el impulso para el sujeto poético: "La sombra sólo y la oquedad habita,/ como su ausencia vanamente inunda/ cuando es ficticio su fulgor y abunda/ la vida que a su sed se precipita." 19

Este cuerpo subjetivo conjuga la ausencia de la imagen con la sed nacida de esa carencia. Es un cuerpo al que podríamos pensar con la delgadez de la imagen y con el corazón de la avidez. Nada aparentemente más frágil y de algún modo más desgarrable que él; es un cuerpo hecho de sombra, carencia y permanente engaño. Pero en el anhelo y la sed encontrará estímulo, fuerza y movimiento. La fortaleza paradójica de este cuerpo radica en que la ausencia y la sed son indestructibles.

Será gracias al armado del poema que se alcance un ser más poderoso. La subjetividad se concibe allí plenamente y deja la piel de ese molde de la ausencia, deja la flaccidez la imagen, su impronta abandonada en el espejo, para nacer a nuevas posibilidades: las del verbo. Gracias a la fábrica del poema se da el salto del cuerpo especular o imaginario hacia la autonomía del verbo. Este nuevo ser se levanta en la compleja articulación del lenguaje poético: ha dejado de ser el cuerpo imagen, hecho de ausencias y pasividad en el espejo, hecho a imagen y semejanza de lo dado, para ganar nueva realidad y libertad.

El sujeto en este momento se despide del espejo, gana libre albedrío, su ser ya es el de las posibilidades infinitas del poema. Con nuevos atributos puede inopinadamente despedirse, es el liberado autorretrato del 'espejo independiente'.

En el 'espejo independiente', Cuesta no se refleja simplemente en el otro rostro, agónico de sí mismo, sino que de alguna manera muere para volver a inventarse. Tanto en el 'espejo independiente' como en el Canto a un dios mineral, el poeta renace. Son alumbramientos

19 "La sombra sólo y la oquedad habita", ibid., p. 49. 
a una suerte de eternidad, triunfos radicales de la voluntad sobre la muerte. ${ }^{20}$

Si Jorge Cuesta es como Robert Desnós que sobrevive a la persecución de lo predeterminado, el espejo poema que es el Canto a un dios mineral se convierte a su vez en un alma independiente, que logra la victoria sobre lo perecedero.

En Cuesta, el alma anhela ser invertida, valgan los dos sentidos del término, en este objeto que es el poema. El alma se invierte de ente inmaterial a materia verbal edificada, por fin visible, y también, usando una metáfora capitalista, gasta allí su ser y su energía como esperando una multiplicación de su ganancia: lo que será un acto de victoria contra la muerte.

Va a existir en el cuerpo verbal de Cuesta una inédita forma de la interioridad, que se conquista mediante una analogía con la arquitectura. Este nueva articulación concertada ya no mimetizará al yo emocional, sino que será espacio exclusivo del objeto poético. La poesía con su ciencia la pone a funcionar. La estructura del lenguaje poético encierra un orden intelectual autónomo, que no es espejo del mundo psíquico.

Esta arquitectura no ofrece el símil de una profundidad especular sirviendo de escenario al mundo anímico del hombre: rompe con el símil del espacio cóncavo o profundo mimetizante de la interioridad psíquica, ya no es espejo del alma humana; sino que se hunde ajena, fascinada, afanosa y aisladamente en sí misma, y se desprende de su creador. El objeto poético se independiza, abandona el simulacro del alma humana.

No estamos ya frente a un mundo imaginario regido pasivamente por un símil especular de la psique. La interioridad del objeto poético busca un ser y una inscripción distintas, independientes del sujeto original. La imagen que se despide ya no vive en un cuerpo fantasma o fantaseado: ha roto la imitación del espacio objetivo junto con la

20 "Ése es el fruto que del tiempo es dueño; en él la entraña su pavor, su sueño/ y su labor termina", ibid., p. 71. 
mímesis de cuerpo y mente humanas. El objeto poético tiene su propia existencia.

Esta interioridad que busca, cual golem, una existencia distinta a la de su creador, invierte su ser en letra escrita, construye su nuevo cuerpo en el enjambre de ecos y espejos que enredan al lenguaje. Gana así consistencia y fuerza propias. Conquista su cuerpo independiente mediante la diamantina arquitectura poética.

Hay en el Canto a un dios mineral una búsqueda que prescindirá de la profundidad espacial como metáfora posibilitadora, e intentará en el arduo trabajo sobre la escritura un cuerpo distinto al de la imagen fugaz. No hay re-presentación en el espejo verbal de Cuesta, hay renacimiento, un renacimiento literal, creación que gracias a la urdimbre de la escritura se arma. 